\title{
Interaction between calcium, neutral endopeptidase and the substance $P$ mediated ciliary response in human respiratory epithelium
}

\author{
R.P. Smith*, R. Shellard**, G. Di Benedetto+, C.J. Magnus ${ }^{++}$, A. Mehta**
}

Interaction between calcium, neutral endopeptidase and the substance $P$ mediated ciliary response in human respiratory epithelium. R.P. Smith, R. Shellard, G. Di Benedetto, C.J. Magnus, A. Mehta. OERS Journals Ltd 1996.

ABSTRACT: Following irritation of the airway, the ciliostimulatory effects of the tachykinin, substance $P$ (SP), are thought to be secondary to mucus release. We hypothesized that SP also induces small increases in ciliary beat frequency (CBF) via a calcium-mediated process.

Brushed ciliated cells from the nasal epithelium of healthy human subjects were suspended in tissue culture fluid and the acute effects of SP upon these cells were studied in a mucus-free environment. In some preparations, changes in CBF in response to SP were measured with a video-based system. The effect of an SP antagonist, of $\mathrm{Ca}^{2+}$ channel block with verapamil, and of the calcium analogue lanthanum on the SP response were also tested. In other preparations, the ciliated cells were preloaded with Fura-2, a dye which fluoresces with $\mathrm{Ca}^{2+}$ ions, and the response of intracellular $\mathrm{Ca}^{2+}$ to $\mathrm{SP}$ was monitored.

SP $\left(1^{-9}-10^{-6} \mathrm{M}\right)$ transiently increased CBF in a dose-dependent manner, with the maximal response occurring at $\mathbf{1 0} \mathrm{min}$. The response was small, with a maximum increase of $8.9 \%$. The SP receptor antagonist (D-pro' $\left.{ }^{2}, \mathrm{D}-\operatorname{trp}^{7,9}\right)-\mathrm{SP}\left(10^{-5} \mathrm{M}\right)$ abolished this effect. Verapamil $\left(10^{-5} \mathrm{M}\right)$ attenuated the response to $\mathrm{SP}\left(10^{-7} \mathrm{M}\right)$, whilst lanthanum chloride $(250 \mu \mathrm{M})$ abolished it. Inhibition of SP destruction by phosphoramidon $\left(1^{-6} \mathrm{M}\right)$ also eliminated the transient rise in $\mathrm{CBF}$. However, compared to SP alone, the combination of SP and phosphoramidon induced a novel delayed lanthanum-sensitive rise in CBF. In other experiments, SP $\left(10^{-7} \mathrm{M}\right)$ induced a transient increase in free intracellular $\mathrm{Ca}^{2+}$ concentration (maximal rise $73 \%$ ), which returned to baseline before the expected onset of the $\mathrm{CBF}$ response.

We conclude that substance $P$ induces either a transient or sustained increase in CBF dependent on the rate of destruction of this peptide around tachykinin receptors. These receptors are likely to be linked to lanthanum- and verapamil-sensitive pathways for the entry of $\mathrm{Ca}^{2+}$ into cells. The small magnitude of the rise in CBF makes its physiological role uncertain at present.

Eur Respir J., 1996, 9, 86-92.
Depts of **Child Health (Centre for Research into Human Development), Ninewells Hospital and Medical School and *Respiratory Medicine, King's Cross Hospital, Dundee. +Dept of Thoracic Medicine, Royal Free Hospital, London, UK, ${ }^{++}$Dept of Pharmacology, School of Pharmacy, London, UK.

Correspondence: A. Mehta

Dept of Child Health

Ninewells Hospital and Medical School Dundee

DD1 9SY

Keywords: Calcium ciliary beat frequency neutral endopeptidase tachykinins

Received: October 211994

Accepted after revision October 71995
Mucociliary clearance is an essential defence mechanism in the respiratory tract by which inhaled and deposited particles, including toxic and infectious agents, are removed from the conducting airways by beating cilia, which propel the overlying secretions towards the oropharynx [1]. Following a noxious stimulus to the nasal airway in vitro, subepithelial sensory $\mathrm{C}$ fibres initiate a local axon reflex which releases neurotransmitters, including the tachykinin peptide, substance P (SP) [2]. This neuropeptide stimulates cell surface receptors and submucous glands to increase chloride [3] and mucus [4] secretion, respectively. Exposure of the canine trachea to substance $\mathrm{P}$ in vivo stimulates ciliary beat frequency $(\mathrm{CBF})$ [5], as does antidromic stimulation of the nerve supply to the maxillary sinus in the rabbit [6]; however, it was thought that these increments in ciliary activity were indirect, secondary to changes in secretion [7]. Thus, the SPinduced rise in tracheal $\mathrm{CBF}$ in vivo is currently assumed to be secondary to a combination of mucus production [4] and net chloride secretion towards the tracheal lumen [3]. This combination may affect the efficiency of the mucociliary interaction by modifying the depth and/or composition of the periciliary fluid layer.

There have been some attempts to circumvent these confounding variables by the determination of the effects of SP on ciliary activity in a mucus-free environment in vitro. However, this approach has itself yielded conflicting results due to one or more of the following: differences in experimental design and or the sensitivity of measurement techniques [8,9], the use of cultured versus fresh cells (from different anatomical sites); and/or interspecies variability in response $[7,10,11]$. Experimental 
design is likely to be of critical importance because the effects of SP on chloride secretion are transient [3], with a rapid onset [12]. The transient nature of these SP responses is thought to be due to the rapid destruction of this peptide by peptidases bound to the luminal membrane (e.g. neutral endopeptidase NEP [13]).

These observations have resulted in the view that SP has no direct effect on ciliary activity either in rabbit airway or human adenoid tissue, despite the cautionary comment from the authors that transient changes could not be excluded using their method [7]. We recently reported such transient stimulatory effects of SP on human cilia [10] using a rather cumbersome photometric technique for the measurement of CBF [14], which has been superseded by video-based equipment [8]. Using this latter technique, we have now extended our studies on the mechanisms by which SP increases CBF.

Our present study thus had four aims: 1) to investigate the time course and dose-response of SP on CBF; 2) to modify this SP response by either: a) receptor blockade with an SP antagonist, (D-pro $\left.{ }^{3}, \mathrm{D}-\operatorname{trp}^{7,9}\right)$-SP; or b) inhibition of SP destruction with phosphoramidon, an inhibitor of the epithelial neutral endopeptidase; 3) to measure changes in intracellular free calcium in the presence of SP; and 4) to determine the effect of calcium channel blockade on the SP response. Our data not only ascribe a new function to the SP receptors on human ciliated respiratory epithelium [15] but also show the complex effects of the rate of SP destruction on the pattern and time course of the SP-dependent ciliary response.

\section{Materials and methods}

\section{Subject selection}

Respiratory epithelium was obtained from nonasthmatic patients aged 7-49 yrs, undergoing routine operations unrelated to nasal disease. Approximately 30\% were smokers. We have previously shown that smoking, local/ general anaesthesia, subject age or cell storage in Medium 199 at $4^{\circ} \mathrm{C}$ have no effect either on basal CBF or its response to dibutyryl cyclic adenosine monophosphate (db-cAMP) in vitro [16]. Local Ethics Committee approval and informed consent were obtained.

\section{Sample collection}

Ciliated epithelium was obtained with a cytology brush from the inferior turbinate, using a technique described by Rutland and Cole [17]. Cellular material adherent to the brush was dislodged by brisk agitation in Eppendorf tubes containing $1 \mathrm{~mL}$ of tissue culture medium (Medium 199; Flow Laboratories, Rickmansworth, UK). All experiments were performed within $4 \mathrm{~h}$ of collection and the samples were kept in Medium 199 at $4^{\circ} \mathrm{C}$ for this period.

\section{Measurement of $C B F$}

$\mathrm{CBF}$ was measured at room temperature using a videobased, Hoffman contrast technique (Brian Reece Scientific, Newbury, Berks, UK). This system permitted the selection of ciliated cell borders either via a video-camera (linked to a television monitor screen) or via the eyepiece of an inverted microscope. Changes in contrast induced by the sweep of the cilia as light was passed downward through the sample chamber were measured. The video signal was relayed to a digitizer software package, which displayed the individual ciliary wave-forms over a $2 \mathrm{~s}$ interval, together with a mean frequency calculated from the number of peaks over this period. The software permitted sampling of the change in contrast induced by the sweep of the cilia at $50 \mathrm{~Hz}$ (complete technical specification available on request). This sampling rate exceeded the typical range of ciliary frequencies observed (4.5-10 $\mathrm{Hz}$ ) by a factor of 5 . When combined with a rigid adherence to the method for cell selection (which provided stable baseline signals, see below), we were able to measure changes in $\mathrm{CBF}$ provided they exceeded $5 \%$ of baseline. However, this degree of precision was only achieved by rejecting data from $50 \%$ of experiments at the stage of the first infusion (unstable baseline, poor signal quality, rise in temperature) and emphasizes the need for a blinded protocol (see below).

The chamber design and perfusion protocol have been described in detail previously $[14,16]$. Aliquots of ciliated cells were transferred in Medium 199 to a glasswalled perfusion chamber with an internal volume of $0.35 \mathrm{~mL}$. The chamber was connected to a gravity feed perfusion system which delivered $0.25 \mathrm{~mL} \cdot \mathrm{min}^{-1}$ and gave a $95 \%$ wash-out of the fluid in the chamber in $10 \mathrm{~min}$. In order to eliminate the increase in CBF induced by perfusion [18], all measurements used for calculation of the results were taken in the absence of flow. The $\mathrm{pH}$ of all solutions tested was 7.2 and 7.4, a range known to have no effect on human ciliary activity [19]. The extracellular $\mathrm{Ca}^{2+}$ concentration was $1.8 \mathrm{mM}$, a value within the range known to have no effect on CBF in rabbit tracheal explants [20].

\section{Cell selection}

Ciliated borders formed by a sheet of 10 or more cells attached to a basement membrane were selected at random and CBF measurements were taken from the same point on the ciliated cell border throughout each experiment. All measurements were taken by an observer who was unaware of the nature of the perfusates. A cell border was considered suitable for study if its CBF signal was sinusoidal (no M-shaped complexes induced by inclusion of the reverse ciliary sweep to the resting position for the next cycle) and returned to its original frequency and waveform within $30 \mathrm{~s}$ of transient changes in flow induced by repeated manual compression of the tubing from the gravity feed. The test substances in the perfusates were studied at room temperature $\left(23 \pm 0.25^{\circ} \mathrm{C}\right)$ in a randomized, blinded protocol, which included a parallel study of an appropriate control solution for each 
experimental set-up, as described in table 1. Ten cell borders were studied from different individuals for each set of experiments, unless otherwise indicated.

\section{Study design}

The study protocol involved a $30 \mathrm{~min}$ period of equilibration in Medium 199 to allow the cell borders to adhere to the glass walls of the chamber. The chamber was then perfused for 10 min with the "baseline" medium, and $\mathrm{CBF}$ measurements were subsequently recorded from the chosen cell border (see above) at 10, 20 and 30 min. "Baseline CBF" was defined as the mean of these three readings. During the "blind" second perfusion, containing either the test substance or control, the change in $\mathrm{CBF}$ was recorded at $5 \mathrm{~min}$ intervals. In order to minimize any light-induced rise in chamber temperature, the microscope was switched off between readings. Chamber temperature was measured continuously with a thermocouple and experiments were rejected if the rise in temperature exceeded $1{ }^{\circ} \mathrm{C}$.

\section{Intracellular calcium measurements}

Intracellular free calcium concentration $\left(\left[\mathrm{Ca}^{2+}\right] \mathrm{i}\right)$ was measured using the fluorescent dye, Fura-2, as described in detail previously [14]. Briefly, cells were loaded with Fura-2 by incubation with a permeant form of the dye $\left(1.0 \times 10^{-6} \mathrm{M}\right.$ acetoxymethyl ester) in Medium 199 for 30 min. The cells were subsequently plated onto poly-Llysine coated $32 \mathrm{~mm}$ square glass coverslips, mounted on the stage of an inverted microscope, and the cells were viewed using a phase-contrast oil immersion fluorescence objective. After selection, each ciliated cell was positioned in the light path of a photomultiplier and the path narrowed to the area of the cell using an iris diaphragm. The cell was then illuminated alternately with 360 and $390 \mathrm{~nm}$ narrow-band filtered light from a $150 \mathrm{~W}$ xenon source fed via fluid-filled light guide, through the epifluorescence port of the microscope. Filters were changed by means of a solenoid operated filter-changer every $250 \mathrm{~ms}$. The light was reflected onto the cell by a $430 \mathrm{~nm}$ dichroic mirror and emitted light passed from the cell through a $470 \mathrm{~nm}$ barrier filter, then a $500 \mathrm{~nm}$ broad-band filter, before reaching the photomultiplier. The photomultiplier signals were fed into a personal computer after digitization. The same equipment also controlled the filter movement. The ratio of the emission signals at 360 and $390 \mathrm{~nm}$ was used to calculate the percentage change (with respect to baseline) in $\left[\mathrm{Ca}^{2+}\right]$ i from the equation:

$$
\left[\mathrm{Ca}^{2+}\right] \mathrm{i}=\mathrm{Kd}(\mathrm{F} 0 / \mathrm{F} 1)(\mathrm{R}-\mathrm{Rmin}) /(\mathrm{Rmax}-\mathrm{R})
$$

Table 1. - Sequence of test substances investigated and summary of results

\begin{tabular}{|c|c|c|c|c|}
\hline $\begin{array}{l}\text { Baseline } \\
\text { perfusate }\end{array}$ & $\begin{array}{l}\text { Second } \\
\text { perfusate }\end{array}$ & $\begin{array}{c}\text { 3aseline CBF } \\
\mathrm{Hz}\end{array}$ & $\begin{array}{c}\text { Change in } \mathrm{CBF} \\
\%\end{array}$ & Comments \\
\hline $\begin{array}{l}\text { A (i) SP dose res } \\
\text { Medium } 199 \\
\text { Medium } 199 \\
\text { Medium } 199 \\
\text { Medium } 199 \\
\text { Medium } 199\end{array}$ & $\begin{array}{l}\text { SP }\left(10^{-9} \mathrm{M}\right) \\
\text { SP }\left(10^{-8} \mathrm{M}\right) \\
\text { SP }\left(10^{-7} \mathrm{M}\right) \\
\text { SP }\left(10^{-6} \mathrm{M}\right) \\
\text { SP }\left(10^{-5} \mathrm{M}\right)\end{array}$ & $\begin{array}{l}7.6 \pm 0.45 \\
6.6 \pm 0.4 \\
6.9 \pm 0.6 \\
6.8 \pm 0.4 \\
6.8 \pm 0.4\end{array}$ & $\begin{array}{l}4.0 \pm 2 \\
6.2 \pm 2.6^{*} \\
7.6 \pm 3^{*} \\
8.2 \pm 1.9 * \\
8.9 \pm 2.1^{*}\end{array}$ & $\begin{array}{l}\text { SP produced a significant rise in CBF } \\
\text { at concentrations of } \geq 10^{-8} \mathrm{M} \text {, which } \\
\text { was maximal at } 10 \mathrm{~min} \text { from the start } \\
\text { of the infusion }\end{array}$ \\
\hline $\begin{array}{l}\text { A (ii) Control } \\
\text { Medium } 199\end{array}$ & Medium 199 & $7.0 \pm 0.41$ & $1.0 \pm 2$ & No effect on baseline \\
\hline $\begin{array}{l}\text { B (i) SP antagon } \\
\text { SPA }\left(10^{-5} \mathrm{M}\right) \\
\text { B (ii) Control }\end{array}$ & SPA $\left(10^{-5} \mathrm{M}\right)+\mathrm{SP}\left(10^{-7} \mathrm{M}\right)$ & $7.6 \pm 0.6$ & $1.6 \pm 1.5$ & SPA inhibited SP-dependent rise \\
\hline Medium 199 & SPA $\left(10^{-5} \mathrm{M}\right)$ & $7.3 \pm 0.5$ & $-1.3 \pm 4$ & No effect on baseline \\
\hline $\begin{array}{l}\text { C (i) Phosphor: } \\
\mathrm{Ph}\left(10^{-6} \mathrm{M}\right)\end{array}$ & $\begin{array}{l}\text { idon } \\
\qquad \mathrm{Ph}\left(10^{-6} \mathrm{M}\right)+\mathrm{SP}\left(10^{-9} \mathrm{M}\right)\end{array}$ & $7.1 \pm 0.3$ & $\begin{array}{l}1.8 \pm 1.0(10 \mathrm{~min}) \\
0.0 \pm 0.8(25 \mathrm{~min})\end{array}$ & No potentiation of SP $\left(10^{-9} \mathrm{M}\right)$ effect \\
\hline $\mathrm{Ph}\left(10^{-6} \mathrm{M}\right)$ & $\left(\mathrm{Ph}\left(10^{-6} \mathrm{M}\right)+\mathrm{SP}\left(10^{-5} \mathrm{M}\right)\right.$ & $6.6 \pm 0.4$ & $12.2 \pm 5^{\dagger}(25 \mathrm{~min})$ & $\begin{array}{l}\text { Early SP-dependent rise replaced by } \\
\text { delayed rise }\end{array}$ \\
\hline $\begin{array}{l}\text { C (ia) } \\
\mathrm{Ph}\left(10^{-6} \mathrm{M}\right)\end{array}$ & $\mathrm{Ph}\left(10^{-6} \mathrm{M}\right)+\mathrm{SP}\left(10^{-6} \mathrm{M}\right)+\mathrm{LaCl}_{3}$ & $36.4 \pm 0.31$ & $2.0 \pm 2(25 \mathrm{~min})$ & Delayed rise inhibited by $\mathrm{LaCl}_{3}$ \\
\hline $\begin{array}{l}\text { C (ii) Control } \\
\text { Medium } 199\end{array}$ & $\mathrm{Ph}\left(10^{-6} \mathrm{M}\right)$ & $6.9 \pm 0.6$ & $2.0 \pm 2$ & No effect on baseline \\
\hline $\begin{array}{l}\text { D (i) Verapamil }{ }^{\#} \\
\text { V }\left(10^{-5} \mathrm{M}\right)\end{array}$ & $\mathrm{V}\left(10^{-5} \mathrm{M}\right)+\mathrm{SP}\left(10^{-7} \mathrm{M}\right)$ & $6.9 \pm 0.5$ & $3.8 \pm 1.9$ & Verapamil attenuated SP-dependent rise \\
\hline $\begin{array}{l}\text { D (ii) } \\
\mathrm{LaCl}_{3}(250 \mu \mathrm{M}) \\
\text { D (iii) Control }\end{array}$ & $\mathrm{LaCl}_{3}(250 \mu \mathrm{M})+\mathrm{SP}\left(10^{-7} \mathrm{M}\right)$ & $7.5 \pm 0.5$ & $-4.8 \pm 2.3$ & $\mathrm{LaCl}_{3}$ inhibited SP-dependent rise \\
\hline Medium 199 & $\mathrm{LaCl}_{3}(250 \mu \mathrm{M})$ & $7.6 \pm 0.5$ & $5.0 \pm 3.1$ & No significant change from baseline \\
\hline
\end{tabular}

Medium 199 was the vehicle used to dissolve all the reagents. All experiments $(n=10)$, except Vpl $+\operatorname{SP}\left(10^{-7} M\right)(n=5)$. Percentage change in CBF represent measurements taken at $10 \mathrm{~min}$ (unless otherwise stated). \#: Verapamil is known to have no effect on baseline $\mathrm{CBF}$ at this concentration [21]. Values are presented as mean \pm SEM. SP: substance P; CBF: ciliary beat frequency; SPA: substance $\mathrm{P}$ antagonist; $\mathrm{Ph}$ : phosphoramidon; $\mathrm{V}$ : verapamil; $\mathrm{LaCl}_{3}$ : lanthanum chloride. *: $\mathrm{p}<0.05$ when compared with control A (ii). $\quad \mathrm{p}<0.05$ when compared with control $\mathrm{C}$ (ii) or with $\mathrm{C}$ (ia). 
where Rmax was the ratio value at saturating calcium, $\mathrm{Rmin}$ the ratio value at limitingly low calcium, $(\mathrm{F} 0 / \mathrm{F} 1)$ the ratio of fluorescence at $390 \mathrm{~nm}$ in low calcium to that in high calcium, and $\mathrm{Kd}$ the calcium dissociation constant for Fura-2 [22]. All recordings were made from cells under continuous gravity-fed perfusion at $0.2 \mathrm{~mL} \cdot \mathrm{min}^{-1}$ with either Medium 199 alone $(n=25)$ or Medium 199 supplemented with SP $\left(10^{-7} \mathrm{M}\right)(\mathrm{n}=25)$. The perfusion outflow tip was positioned within $200 \mu \mathrm{m}$ of the cell and complete solution changes in the region of the cell were achieved within $2 \mathrm{~s}$.

\section{Chemical reagents}

Medium 199 and Fura-2 were obtained from Flow Laboratories (Rickmansworth, UK) and Molecular Probes Inc. (Eugene, OR, USA), respectively. SP, (D-Pro ${ }^{3}, \mathrm{D}-$ Trp $\left.{ }^{7,9}\right)-\mathrm{SP}$, phosphoramidon (Phos), verapamil, $\mathrm{LaCl}_{3}$ and poly-L-lysine were purchased from Sigma (Poole, UK). Medium 199 was the vehicle used to dissolve all the reagents.

\section{Statistical analysis}

The randomization protocol for the selection of the cell border resulted in a variation in baseline CBF between experiments. Thus, in order to compare results between experiments, the $\mathrm{CBF}$ responses observed were expressed as percentage changes from baseline values. The mean \pm SEM was calculated for the percentage change from baseline both for the $\mathrm{CBF}$ and the $\left[\mathrm{Ca}^{2+}\right]$ i measurements. Analysis of variance (ANOVA) was used to compare the CBF responses to different infusions; comparisons at individual time-points between experimental and control groups were made using the Mann-Whitney U-test. Significance was accepted when $\mathrm{p}$ was less than 0.05 .

\section{Results}

\section{Substance P time-course and dose-response}

SP (but not control) produced a transient elevation in $\mathrm{CBF}$, which was maximal at $10 \mathrm{~min}$ and returned to baseline by $30 \mathrm{~min}$ (fig 1). SP $\left(10^{-9}-10^{-5} \mathrm{M}\right)$ increased CBF in a dose-dependent manner (fig. 2 and table 1A), with a maximal increase of $8.9 \pm 2.1 \%$ from baseline at $10 \mathrm{~min}$. This response was significantly different from control at concentrations above $10^{-8} \mathrm{M}(\mathrm{p}<0.05)$. In addition, the $\mathrm{CBF}$ response to SP $\left(10^{-9}-10^{-6} \mathrm{M}\right)$ was recorded during the period of infusion (fig. 1) in order to confirm that the maximal rise in $\mathrm{CBF}$ had indeed occurred at $10 \mathrm{~min}$ from the start of the infusion.

\section{Effect of substance P on intracellular free calcium}

In order to explore the mechanism underlying this SP response, the cells were loaded with the fluorescent dye, Fura-2. Exposure of the cells to control solution did not significantly affect basal $\left[\mathrm{Ca}^{2+}\right] \mathrm{i}$, an effect we have also

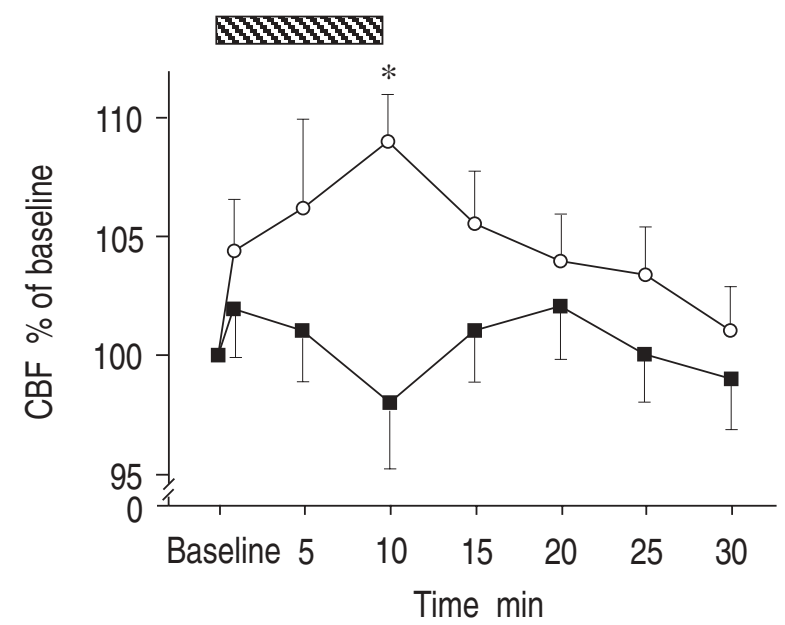

Fig. 1. - Time course of substance P (SP) effect on ciliary beat frequency $(\mathrm{CBF})$. Values are expressed as mean (SEM) percentage change from baseline $\mathrm{CBF}$ (mean $7.4 \mathrm{~Hz}$ range $5.75-9.0 \mathrm{~Hz}$ ) which is shown as $100 \%$. : control (Medium 199 only); $\square$ SP $10^{-6} \mathrm{M} ;(\mathrm{n}=10)$. Figure includes measurement taken during period of infusion represented by hatched bar, i.e. time-points 1 and $5 \mathrm{~min}$. *: $\mathrm{p}<0.05$ compared to control.

reported previously [14]. SP $\left(10^{-7} \mathrm{M}\right)$ induced an immediate and statistically significant increase in $\left[\mathrm{Ca}^{2+}\right] \mathrm{i}(+73 \pm$ $8 \%$ at $1 \mathrm{~min}(\mathrm{p}<0.01))$, which was followed by a return to baseline values by $7 \mathrm{~min}$ of perfusion (fig. 3). Measurements of $\left[\mathrm{Ca}^{2+}\right]$ i before 1 min were not carried out.

\section{Inhibition of the SP response}

Infusion with the SP antagonist, (D-Pro $\left.{ }^{3}, \mathrm{D}-\mathrm{Trp}^{7,9}\right)-\mathrm{SP}$ $\left(10^{-5} \mathrm{M}\right)$, alone did not affect baseline CBF but completely abolished the rise expected with $\mathrm{SP}\left(10^{-7} \mathrm{M}\right)$ (table 1B). This SP response was also abolished by calcium channel blockade (table 1D) with the nonpermeant calcium analogue, lanthanum chloride $(250 \mu \mathrm{M})$. However, verapamil $\left(10^{-5} \mathrm{M}\right)$, an antagonist of voltage-gated calcium channels, had only a partial inhibitory effect, limiting the rise in $\mathrm{CBF}$ with $\mathrm{SP}\left(10^{-7} \mathrm{M}\right)$ to $4.4 \pm 1.9 \%$. Neither verapamil [21] nor lanthanum chloride (table 1Diii) altered baseline CBF in the absence of SP.

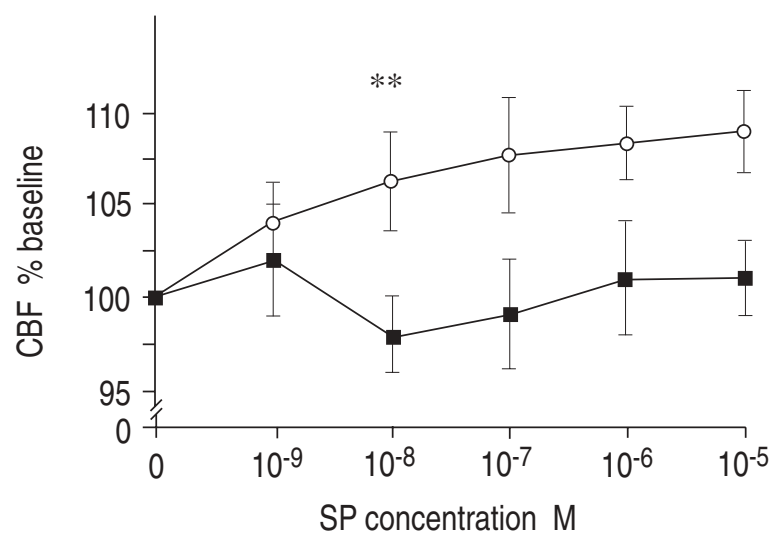

Fig. 2. - Substance P (SP) dose response. The mean (SEM) percentage change from baseline ciliary beat frequency $(\mathrm{CBF})$ at $10 \mathrm{~min}$ from start of infusion comparing SP $10^{-9}-10^{-5} \mathrm{M}(-\mathrm{O}-$ ) with control ( $) ;(\mathrm{n}=10)$. *: $\mathrm{p}<0.05$ for concentrations of $10^{-8} \mathrm{M}$ or above. 


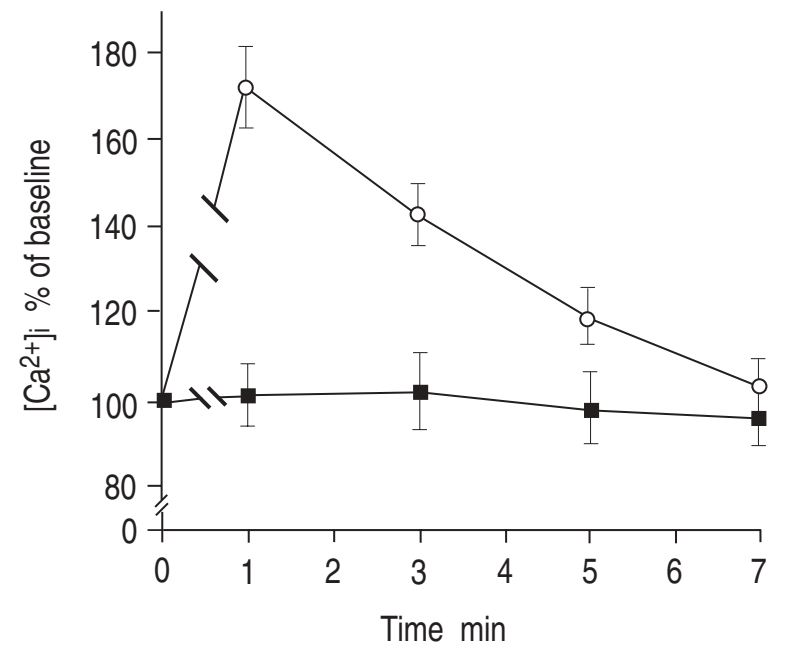

Fig. 3. - Effect of substance P (SP) on intracellular calcium. The mean (SEM) percentage change in intracellular free calcium concentration $\left[\mathrm{Ca}^{2+}\right] \mathrm{i}$, estimated using a Fura- 2 fluorescence technique, in respiratory epithelial cells when exposed to SP $10^{-7} \mathrm{M}$ (- - ) versus control ( $)$; $(\mathrm{n}=25), * *: \mathrm{p}<0.05$ compared to baseline and control.

\section{Inhibition of SP destruction}

In order to explore the mechanisms underlying the transient response to SP, the destruction of this tachykinin was inhibited with the neutral endopeptidase inhibitor, phosphoramidon $\left(10^{-6} \mathrm{M}\right)$, which alone had no effect on baseline CBF (table 1C). We did not observe the expected augmentation of the SP response with a shift to the left of the dose-response curve. Instead, this inhibitor produced two unexpected effects when co-infused with SP $\left(10^{-5} \mathrm{M}\right)$ (fig. 4). Firstly, phosphoramidon abolished the expected, transient $\mathrm{CBF}$ response to $\mathrm{SP}$ (i.e. at 10 $\min )$. Secondly, this transient response was replaced by a delayed rise in $\mathrm{CBF}$ with a maximal value of $12.2 \pm 5 \%$

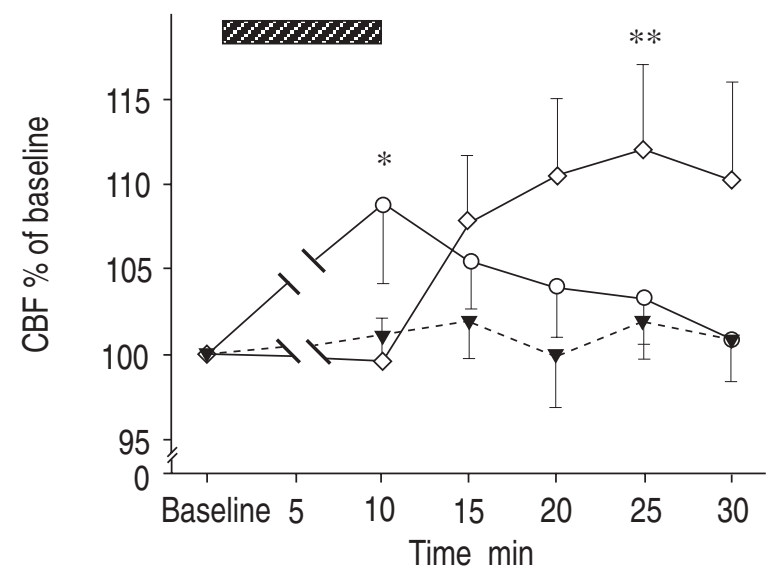

Fig. 4. - The effect of neutral endopeptidase inhibition on the substance P (SP) ciliary beat frequency response. The mean (SEM) percentage change in $\mathrm{CBF}$ following infusion (hatched bar) with: 1) SP $\left(10^{-6} \mathrm{M}\right)(\longrightarrow)$; 2) phosphoramidon $\left(10^{-6} \mathrm{M}\right)+\mathrm{SP}\left(10^{-5} \mathrm{M}\right)$ $\left(\checkmark-\right.$ ); or 3) phosphoramidon $\left(10^{-6} \mathrm{M}\right)+\mathrm{SP}\left(10^{-6} \mathrm{M}\right)+$ lanthanum chloride $(250 \mu \mathrm{M})(\ldots-\ldots)$; $(\mathrm{n}=10)$. * $\mathrm{p}<0.05$, SP response compared with SP + phosphoramidon at $10 \mathrm{~min}$; **: $\mathrm{p}<0.05$, SP + phosphoramidon response compared with $\mathrm{SP}+$ phosphoramidon + lanthanum chloride at $25 \mathrm{~min}$. The control infusion with Medium 199 alone was not significantly different from the dotted line ( . . - $\mathbf{\nabla . - .})$ and is not shown, for clarity. at 25 min postinfusion. This delayed rise was itself abolished when the calcium channel antagonist lanthanum chloride $(250 \mu \mathrm{M})$ was co-infused with the SP-phosphoramidon combination (fig. 4), suggesting that calcium entry was required for its generation.

\section{Discussion}

\section{SP and ciliary activity}

Our results show that $\mathrm{SP}$ induces a rise in $\mathrm{CBF}$ in human respiratory tract epithelium in a mucus-free environment in vitro. This conclusion supports similar observations using SP in human adenoid explants [11]. We found the $\mathrm{CBF}$ response to be rapid, with maximal $\mathrm{CBF}$ values at the end of the $10 \mathrm{~min}$ infusion period. In vivo, micromolar concentrations of SP are believed to act via direct stimulation of neurokinin receptors [13], and our dose response curve is compatible with this model. We also observed that the tachykinin receptor antagonist, SPA, (D-Pro $\left.{ }^{3}, \mathrm{D}-\mathrm{Trp}^{7,9}-\mathrm{SP}\right)$, inhibited the SP-dependent rise in $\mathrm{CBF}$, which is consistent with a receptor-mediated process. The rise in $\mathrm{CBF}$ with SP was transient and we presumed that the action of neutral endopeptidase (located in the apical epithelial cell membrane and known to rapidly degrade such peptides in vivo [23]) was responsible for the decline in the SP response over $30 \mathrm{~min}$. It was with this hypothesis in mind that we explored the effects of SP in the presence of the neutral endopeptidase inhibitor, phosphoramidon.

Our expectations were that phosphoramidon would potentiate and/or prolong the SP effect on CBF and we were surprised to find that the combination of SP and this neutral endopeptidase inhibitor not only abolished the transient SP response, but also induced a delayed and more sustained rise in CBF (fig. 4). This response, occurring in the likely setting of sustained SP receptor stimulation, cannot be readily explained. We do not believe that it is artefactual because we have preliminary data suggesting that a similar delayed rise in CBF occurs when phosphoramidon is replaced with thiorphan, another inhibitor of neutral endopeptidase (Smith and Mehta, unpublished observations). Our data suggest that sustained receptor stimulation is more complex than is currently appreciated. Although phosphoramidon itself has no direct effect on baseline CBF, it is possible that by influencing the molar ratio between SP and one or more surface receptors, the expressed intracellular signal is fundamentally affected, with a resultant change in CBF pattern. The use of the newer, selective antagonists of the different subclasses of SP receptor might unravel the mechanism underlying the delayed response.

However, the second messenger cascades involved in the SP response are extremely complex, as demonstrated by recent studies, which propose a role for prostaglandin release $[24,25]$ and nitric oxide synthesis [26] in the ciliostimulatory effects of this tachykinin. Interestingly, it has also been shown that when cloned tachykinin receptors were functionally expressed, inhibition of the release of inositol 1,4,5-triphosphate (and hence of calcium from intracellular stores), occurred as receptor occupancy increased [12]. 


\section{Calcium and the $S P$ response}

It is well-recognized that $\mathrm{Ca}^{2+}$ plays an important part in the regulation of human ciliary activity [9, 14, 27]. The molecular structures of tachykinin receptors suggest that their activities are mediated by stimulation of phospholipase $\mathrm{C}$ and the release of intracellular calcium [12]. Our findings are consistent with a role for calcium as a mediator for the effects of SP. The Fura- 2 studies, albeit conducted separately from the ciliary experiments, demonstrated an immediate rise in intracellular calcium following SP stimulation, suggesting a role for this ion as a second messenger mediating the physiological effect of SP. In other systems, it is known that the triphosphate derivatives of inositol are released when SP activates the neurokinin-1 (NK-1) receptor and an oscillatory inward membrane current is generated within seconds of receptor occupancy, which ranges from $50 \mathrm{nA}$ to $1 \mu \mathrm{A}$ [12]. However, the maximal $\mathrm{CBF}$ response appeared to lag behind the rise in intracellular $\left[\mathrm{Ca}^{2+}\right] \mathrm{i}$, but it is difficult to compare these observations directly because the two measurements were not made together. This postulated time-lag has, however, been demonstrated in cultured rabbit airway epithelium using a novel approach which measured $\mathrm{CBF}$ and $\left[\mathrm{Ca}^{2+}\right] \mathrm{i}$ simultaneously [27]. This method could, in future, be used to determine the effects of phosphoramidon on $\left[\mathrm{Ca}^{2+}\right]$ i in human respiratory epithelium.

An early rise in intracellular calcium is not unexpected for a receptor-mediated phenomenon, and the rapidity of the calcium rise suggests release of internal calcium stores rather than calcium influx into the cell as the initial event. However, in our study, the increase in CBF elicited by SP was reduced by the calcium-channel blocker, verapamil, and abolished with lanthanum, which is a high affinity calcium analogue. Neither agent inhibited baseline $\mathrm{CBF}$ in the absence of SP, suggesting that the calcium channels involved in the SP response are distinct from the pathways regulating basal CBF (see paragraph below). Our data are consistent with the notion that the ciliary SP effect is dependent on calcium influx. Furthermore, it appears likely that the entry of extracellular calcium also plays an important role in the delayed rise in CBF observed with SP (in the presence of phosphoramidon) because co-infusion of lanthanum chloride, SP and phosphoramidon abolished this delayed response (table 1 and fig. 4).

Interestingly, the time-course of this delayed CBF rise was very similar to our earlier findings with calcium ionophore A23187 [14]. These earlier experiments showed that the delayed rise in CBF with A23187 was abolished by preincubation of the cells with trifluoperazine (TFP), an inhibitor of calmodulin-dependent phosphorylation pathways [14]. However, in that study, TFP also reduced basal $\mathrm{CBF}$ in the absence of ciliostimulants, an effect not reproduced with verapamil or lanthanum chloride in the present study. The verapamil data suggest that, in the short-term at least, inhibition of calcium entry through voltage-gated channels does not change CBF significantly. Currently, there is debate over the relationship between polyphosphoinositol products (released by SP), the inositol triphosphate $\left(\mathrm{InsP}_{3}\right)$ receptors on the endoplasmic reticulum, the release of intracellular calcium stores and calcium entry into the cytoplasm [28]. Our results suggest that the simultaneous measurement of the delayed SP-dependent ciliary response and intracellular calcium concentration may help to explain stimulus-response coupling of calcium-mediated events in respiratory epithelial physiology.

\section{Differences in experimental design and the detection of the SP response}

We have found a transient rise in CBF following stimulation with SP using two different methods [10], which contradicts the findings of earlier investigators who reported that SP alone failed to elucidate a rise in $\operatorname{CBF}[7,29]$. KonDo et al. [29] did, however, demonstrate that SP increased CBF (in rabbit) in the presence of the neutral endopeptidase inhibitor, thiorphan. This may be explained either by thiorphan inducing a similar delayed response, thus facilitating the detection of a late rise in CBF or by interspecies variation. The failure of other investigators to detect SPmediated changes in CBF is readily explained by their experimental design, which compared the mean frequency of cell borders from two separate aliquots of cells (from the same brushing): i.e. the mean of CBF measurements taken from 10 different cell borders within one aliquot (immersed in control solution) were compared with the mean of the 10 readings taken from a separate aliquot (immersed in the experimental solution). We believe that the technique employed in our studies, which tracks a stable group of cilia along a given cell border over time, allows more accurate measurements of $\mathrm{CBF}$ and is more suitable for examining time-dependent modulation of CBF [30].

\section{Physiological significance of SP}

SP belongs to the tachykinin family of peptides, which derive their name from their stimulatory effects on gastrointestinal motility [31]. In the lung, SP is localized predominantly to capsaicin-sensitive unmyelinated nerves and its actions are mediated via NK-1 receptors (with lesser activity through neurokinin-2 (NK-2) receptors). It has a number of physiological effects $[13,32]$, which include augmentation of smooth muscle tone, mucus secretion, local blood flow, vascular permeability, mast cell degranulation and eosinophil migration. SP may also activate alveolar macrophages [33]. Although the pathophysiological significance of these effects is not defined, it has been observed that the nerve fibres which release SP are hypertrophied in asthmatic airways [34], and it has been suggested that the peptide may be an important mediator in the pathogenesis of this disease [13]. Inhaled SP has also been demonstrated to increase tracheal CBF in vivo in dog models [5], and the close proximity of the SP nerve endings with the basolateral epithelial cell membrane makes the neuropeptide an ideal candidate to mediate the rapid clearance of injurious chemical or bacteriological agents trapped in the over-lying mucus. Some investigators have proposed that SP does not directly stimulate ciliary beating [7], and that any increase in $\mathrm{CBF}$ in vivo is secondary to the known effects of increased mucus secretion or to modification of the composition of the periciliary fluid layer [35]. 
In conclusion, our in vitro studies are at variance with the early studies on the response of ciliated epithelial cells to SP. We find that SP increases CBF in human nasal respiratory cells and that this effect is likely to result from direct action on tachykinin receptors. This rise in $\mathrm{CBF}$ is attenuated by verapamil (an antagonist of voltage-gated calcium channels) and abolished by the calcium analogue, lanthanum chloride, which is consistent with the notion that SP-induced effects may be, in part, dependent on calcium influx. Our finding that the SP-phosphoramidon combination not only changes the pattern of the CBF response but eliminates the transient SP-mediated rise is puzzling, requires explanation and forms the focus of our current work.

Acknowledgements: The authors thank the Chest Research and Education Fund (D.P. Dhillon and J.H. Winter) and the Anonymous Trust (Dundee) for equipment and running costs, the Sir Jules Thorn Trust for the initial collaboration between the research groups, and P.J. Kemp and R.E. Olver for critical review of the manuscript. We thank theatre staff for their help.

\section{References}

1. Sleigh MA, Blake JR, Liron N. The propulsion of mucus by cilia. Am Rev Respir Dis 1988; 137: 726-741.

2. Baraniuk JN, Kaliner M. Neuropeptides and nasal secretion. Am J Physiol 1991; 261: L223-L235.

3. Al-Bazzaz FJ, Kelsey JG, Kaage WD. Substance P stimulation of chloride secretion by canine tracheal mucosa. Am Rev Respir Dis 1985; 131: 86-89.

4. Baker AP, Hilegass LM, Holden DA, Smith WJ. Effect of kallidin, substance $\mathrm{P}$, and other basic polypeptides on the production of respiratory macromolecules. Am Rev Respir Dis 1977; 115: 811-817.

5. Wong LB, Miller IF, Yeates DB. Pathways of substance $\mathrm{P}$ stimulation of canine tracheal ciliary beat frequency. J Appl Physiol 1991; 70 (1): 267-273.

6. Lindberg S, Mercke U. Antidromic nerve stimulation accelerates mucociliary activity in rabbit maxillary sinus. Acta Otolaryngol 1986; 101: 484-493.

7. Khan AR, Bengtsson B, Lindberg S. Influence of substance $\mathrm{P}$ ciliary beat frequency in airway isolated preparations. Eur J Pharmacol 1986; 130: 91-96.

8. Rusznak C, Devalia JL, Lozewicz S, Davies RJ. The assessment of nasal mucociliary clearance and the effect of drugs. Respir Med 1994; 88: 89-101.

9. Lansley AB, Sanderson MJ, Dirksen ER. Control of the beat cycle of respiratory tract cilia by $\mathrm{Ca}^{2+}$ and cAMP. Am J Physiol 1992; 263: L232-L242.

10. Di Benedetto G, Yiangou Y, Spiteri MA, Clarke SW. Substance $\mathrm{P}$ increases the activity of human respiratory cilia in vitro. Eur Respir J 1991; 4 (Suppl. 14): 291S.

11. Staskowski PA, Mccaffrey TV. Effect of substance P on ciliary beat frequency in human adenoid explants. Otolaryngol Head Neck Surg 1992; 107: 553-557.

12. Krause JE, Takeda Y, Hershey AD. Structure, functions and mechanisms of substance $\mathrm{P}$ receptor action. J Invest Dermatol 1992; 98: 2S-7S.

13. Barnes PJ. Neuropeptides and asthma. In: Kaliner MA, Barnes PJ, Kunkel GHH, Baraniuk JN, eds. Neuropeptides in Respiratory Medicine. New York, Marcel Dekker, 1994; pp. 501-544.

14. Di Benedetto G, Magnus CJ, Gray PTA, Mehta A.
Calcium regulation of ciliary beat frequency in human respiratory epithelium in vitro. J Physiol 1991; 439: 103-113.

15. Goldie RG. Receptors in asthmatic airways. Am Rev Respir Dis 1990; 141: S151-S156.

16. Di Benedetto G, Manara-Shediac FS, Mehta A. Effect of cyclic AMP on ciliary activity of human respiratory epithelium. Eur Respir J 1991; 4: 789-795.

17. Rutland J, Cole PJ. Noninvasive sampling of nasal cilia for measurement of beat frequency and study of ultrastructure. Lancet 1980; ii: 564-565.

18. Di Benedetto G, Lopez-Vidriero MT, Clarke SW. The effect of perfusion flow-rate on ciliary activity in vitro. Bull Eur Physiopathol Respir 1987; 23 (Suppl. 12): 364S.

19. Luk CK, Dulfano MJ. Effect of $\mathrm{pH}$, viscosity and ionicstrength changes on ciliary beating frequency of human bronchial explants. Clin Sci 1983; 64: 449-451.

20. Girard PR, Kennedy JR. Calcium regulation of ciliary activity in rabbit tracheal epithelial explants and outgrowth. Eur J Cell Biol 1986; 40: 203-209

21. Di Bennedetto G, Magnus CJ, Clarke SW. The effect of verapamil on the ciliary response to substance $\mathrm{P}$ in human respiratory epithelium. Eur Respir J 1992; 5 (Suppl. 15): 189S.

22. Grynkiewicz G, Poenie M, Tsien RY. A new generation of $\mathrm{Ca}^{2+}$ indicators with greatly improved fluorescence properties. J Biol Chem 1985; 260: 3440-3450.

23. Nadel JA. Neutral endopeptidase modulates neurogenic inflammation. Eur Respir J 1991; 4: 745-754.

24. McCaffrey TV, Yang B, Schlosser RJ. Prostaglandin $E_{2}$ modulates ciliary beat frequency in human upper airway mucosa by production of endogenous nitric oxide. FASEB J 1995; 9: A146.

25. Czaja JM, Schlosser RJ, McCaffrey TV. Substance P stimulates human respiratory cilia by production of endogenous prostaglandins. Faseb J 1995; 9: A147.

26. Schlosser RJ, Yang B, McCaffrey TV. Substance P stimulates human respiratory cilia by production of endogenous nitric oxide. Faseb J 1995; 9: A147.

27. Korngreen A, Priel Z. Simultaneous measurement of ciliary beating and intracellular calcium. Biophys J 1994; 67: $377-380$.

28. Irvine RF. Inositol phosphates and calcium entry towards a proliferation or a simplification? Faseb J 1992; 6: 3085-3091.

29. Kondo M, Tamaoki J, Takiza WAT. Neutral endopeptidase inhibitor potentiates the tachykinin-induced increase in ciliary beat frequency in rabbit trachea. Am Rev Respir Dis 1990; 142: 403-406.

30. Di Benedetto G, Mehta A. Variability of human ciliary beat frequency in vitro. Eur Respir J 1990; 3: 257S.

31. Pernow B. Substance P. Pharmacol Rev 1983; 35: 85-129.

32. Matsuda H, Kawkita K, Kiso Y, Kitamura Y. Substance $\mathrm{P}$ induces granulocyte infiltration through degranulation of mast cells. J Immunol 1989; 142: 927-931.

33. Brunelleschi S, Vanni L, Ledda F, Giotti A, Maggi CA, Fantozzi R. Tachykinins activate guinea pig alveolar macrophages: involvement of NK-2 and NK-1 receptors. Br J Pharmacol 1990; 100: 417-420.

34. Ollerenshaw SL, Jarvis D, Sullivan CE, Woolcock AJ. Substance P immunoreactive nerves in airways from asthmatics and nonasthmatics. Eur Respir J 1991; 4: 673-682.

35. Sanderson MJ, Dirksen ER. Mechanosensitive and betaadrenergic control of the ciliary beat frequency of mammalian respiratory tract cells in culture. Am Rev Respir Dis 1989; 139: 432-440. 